\section{ICT and agriculture}

\author{
Madhura Swaminathan $^{1} \cdot$ M. S. Swaminathan ${ }^{2}$
}

Published online: 8 September 2018

(c) CSI Publications 2018

A felt need of farmers is timely availability of information on technology, monsoon behaviour and market opportunities. Regular extension services usually do not reach the farmer at the right time and place. Modern information and communication technology (ICT) allows new possibilities to overcome the information gap from which rural households, farmers, fisherfolk and women suffer.

Recognising the potential of new technologies and in order to ensure that information transfer through ICT is done in a scientific manner, the M S Swaminathan Research Foundation (MSSRF) organised a Dialogue on "Reaching the Unreached: Information Technology" in 1991 at Chennai [1]. This was the beginning of our efforts to bring in ICT in the area of production and post-harvest management particularly for excluded sections of the population, the rural poor, farm men and women, and fisherfolk.

As M. S. Swaminathan wrote in 1993,

Taking the benefits of new technologies to economically and socially disadvantaged sections of the rural population is thus a pre-requisite for promoting a new paradigm of rural development...Information, in the field of agriculture, to be of benefit has to be tailored to local agro-ecological and socio-economic conditions. It has to be backed up by relevant input supply

Madhura Swaminathan

madhura@isibang.ac.in

M. S. Swaminathan

swami@mssrf.res.in

1 Economic Analysis Unit, Indian Statistical Institute, Bangalore, India

2 M.S. Swaminathan Research Foundation, Taramani, Chennai, India services and public policies Synchronisation in time and space between knowledge and input delivery systems is essential to impart credibility to the extension message...All this calls for a systems approach to knowledge and skill dissemination systems.

He further stated that, "The emerging ecological agricultural systems are more knowledge-intensive since they aim to substitute knowledge and biological inputs for chemicals and capital. An effective information system is essential to promote and sustain ecological farming." (pp vii-viii)

This special issue on ICT and Agriculture discusses a range of technologies and their application to problems of agriculture, particularly to problems of the poorer sections of the rural population. The traditional extension system follows what has been called a lab-to-land approach, that is, a system of taking science from laboratories and scientists out to farmers. The ICT applications discussed in this volume allow integration of traditional extension with land-to-land (farmer-to-farmer) and land-to-lab (user feedback) approaches.

Following the interdisciplinary dialogue, a consortium of interested organisations was formed and a project to start information villages was begun. It is in this context that MSSRF started Village Knowledge Centres in Puducherry in 1993. The first of these knowledge centres was inaugurated by Dr Bruce Alberts, the then President of the US National Academy of Sciences, who spoke of a new dawn in the knowledge transformation of agriculture. The paper by Nancy Anabel, Priyanka Mohan and Rajkumar outlines the hub and spokes model for ICT in agriculture that was developed in order to expand ways of knowledge dissemination. The Village Resource Centre in one main village 
acts as the hub, identifying information needs of farm men and women, and then preparing the required information inputs and delivering it to the spokes, the Village Knowledge Centres in several outlying villages. The connection between hub and spokes was via satellite communication using VSAT and radios. As the authors show, farmers appreciated the timely information on both meteorological factors and market conditions.

The use of ICT is important not only in crop farming but can revolutionize small scale fisheries. The paper on Fisher Friend Mobile Application by Anabel, Velvizhi, and Suvitha, shows how a mobile phone application was developed to assist fisher families after the tsunami of 2004. Fisherfolk were very worried and tense about conditions at sea, in particular, the height of waves, in the posttsunami period. Using a participatory approach, MSSRF along with TCS and Qualcomm developed an application on a CDMA platform that would provide real time information to fishermen. Today, the android version of Fisher Friend is available on Google play store and thousands of fisherfolk use it every day. Multiple partners are involved (the Indian Meteorological Department and the Indian National Centre for Ocean Information Services or INCOIS, to name a few) in providing updated real-time information. The fishermen carry mobile phones which give them information on wave heights at different distances from the shoreline even before they embark on their journey. There is also information to help increase fish catch and on safety and danger zones including on the international maritime border. As the authors demonstrate, this application has helped fisher families in reducing risk and raising returns.

During the last 20 years, we have seen unprecedented changes in information and communication technology and in partnerships between the public and private sectors. Rural India too has been affected though there remains a substantial rural-urban divide. The proportion of rural households consuming electricity rose from $34 \%$ in 1993-94 to 74\% in 2011-12 (and has probably risen further). Per capita electricity consumption rose from 2.27 to $8.92 \mathrm{kWh}$ over the same period. By international standards, India's per capita electricity consumption is still very low, the lowest among BRICS nations, and one-third of the world average.

Ownership of assets including radio, television, telephone and computer is recorded by the Census of India. Between 2001 and 2011, the proportion of rural households owning radios went down from 31.5 to $17 \%$ while the proportion of those owning televisions went up from 18.9 to $33.4 \%{ }^{1}$ The corresponding proportions for telephones

\footnotetext{
1 According to BARC, there were 99 million rural homes with televisions in 2017 but viewership was higher [6].
}

went from 4 to $54 \%$. Data on computers was not collected in 2001. In 2011, 5\% of rural households owned computers. The most notable change is of course with respect to the telephones. Rural teledensity defined as the ratio of wireless and wireline communication subscribers per 100 rural persons went from $38 \%$ in December 2011 to $57 \%$ in May 2018 [2-4]. Nevertheless, in 2018, rural telephone subscribers accounted for only $44 \%$ of all subscribers (although being $69 \%$ of total population). What is of note, however, is that $99.3 \%$ of rural telephone subscribers used wireless or mobile phones. Data from the Indian Market Research Bureau, suggest that there were an estimated 109 million mobile internet users in rural India, though the large majority of them use the internet mainly for social network websites and for email [5].

As technology changed, applications changed.

Van Mele et al. examine videos for farmer training, especially in the context of South-South knowledge sharing. They discuss the model of Access Agriculture, an international NGO, which hosts a video platform with training videos in several languages available for free download. Access has trained local NGOs in Asia and Africa in the production of such videos. Another model is that of Plant Clinics developed by CABI which uses tablets with pre-loaded information to diagnose problems particularly of pests and diseases that hamper crop growth. The application of community-based plant clinics in Tamil Nadu is reported in the paper by Thamizoli, Balasubramanian, Onyango, Kamaraj and Rengalakshmi.

The use of social media by agricultural extension professionals is a new application, discussed by Bhattacharjee and Raj. Their paper is based on data collected globally from over 500 agricultural extension professionals, and argues that the new technology provides easier user interface than earlier. However, to be an effective tool for agriculture communication, many policy and organisational changes are needed. To take an example, we need guidelines for stakeholders on social media use to ensure safe online engagement. Another paper on social media by Carr et al. looks at the other end of the spectrum, that is, farmers using Facebook, in order to understand the horizontal transfer of knowledge. The study finds that social media did facilitate transfer of knowledge but interestingly, the same information was shared offline too, and online learning was enhanced by face to face sharing of information. Further, while the new technology provides an opportunity for interactive learning, social media is also limited by existing social differentiation such as gender and caste differentiation

The latest use of wireless sensor networks technology for precision agriculture - an application of the Internet of Things (IoT) to farming-is discussed by Koshy et al. The paper present two case studies of the use of IoT for 
forewarning of pests and diseases in groundnut cultivation. Clearly, emerging technologies offer immense scope for customisation to local needs.

One advantage of ICT is that it is gender neutral. The experiences discussed in this volume show that women accept new technology as much as men. Women farmers use cutting-edge technologies like tablet-based android applications proficiently for diagnosing plant health issues in diverse crops through the plant clinic initiative and provide appropriate and environmentally and economically viable solution to fellow farmers. The gender needs of information can also be taken into account since women play a leading role in post-harvest management of crops and animal products. The paper by Thamizoli et al. examines how mobile phones can be used for lifelong learning, drawing on the experience of a programme in Tamil Nadu among women engaged in livestock raising. Based on their requirements, the women received several voice messages in a day with relevant information. One of the major advantages of mobile phone based learning is the portability of the instrument, which allows for tremendous flexibility in time use (and learning time). Engendering technology development and transfer becomes much more possible in the case of ICT.

Looking back over 25 years, since the first use of ICT in Embalam village of Puducherry, today, the information age is upon us and brings huge possibilities for ICT in agriculture. The challenge is to ensure that the latest information and communication technologies are combined with appropriate changes in institutions and policies so as to make a dent on the information divide, not just the ruralurban divide but the divide between economically and socially disadvantaged groups and others. Even if technology is gender-neutral or caste-neutral, technology is embedded in society and cannot on its own address problems of socio-economic development, such as the information gap experienced by historically disadvantaged social groups [7].
There are now many government initiatives to promote the use of ICT especially in respect of empowering Panchayati Raj institutions through information. In our view, the era of knowledge empowerment through ICT is as yet in the early stages of development. The effort in this volume is to take stock, to document, and assess different ICT applications in the field of agriculture and allied activities, primarily in India but elsewhere too.

For this special edition of CSI Transactions, an editorial team was formed comprising Madhura Swaminathan, Priyanka Mohan, Nancy J Anabel and Rengalakshmi. We would like to thank this team for putting the issue together. We also thank Dayanandham for secretarial support.

\section{References}

1. Swaminathan MS (ed) (1993) Information technology: a dialogue. Macmillan India Limited, Madras

2. TRAI, Telecom Regulatory Authority of India (2011) Highlights of Telecom Subscription Data as on 31st May, 2011. Press Release No. 41/2011. New Delhi. https://www.trai.gov.in/release-publica tion/reports/telecom-subscriptions-reports

3. Telecom Regulatory Authority of India (2017) The Indian Telecom Services Performance Indicators April-June, 2017. New Delhi. https://www.trai.gov.in/release-publication/reports/perfor mance-indicators-reports

4. TRAI, Telecom Regulatory Authority of India (2018) Highlights of Telecom Subscription Data as on 31st May, 2018. Press Release No. 81/2018. New Delhi. https://www.trai.gov.in/release-publica tion/reports/performance-indicators-reports

5. IMRB, Technology Division (2016) Internet in India-2016 An IAMAI and KANTAR IMRB Report. IAMAI, Maharashtra and Kantar IMRB, Bangalore. www.iamai.in

6. Srivastava A (2018) TV viewership in India: March 2017-BARC Broadcast India Survey. https://marketinglessons.in/tv-viewershipindia-barc-2017/

7. Kamath A (2018) "Untouchable" cellphones? Old caste exclusions and new digital divides in peri-urban Bangalore. Crit Asian Stud 50(3):375-394. https://doi.org/10.1080/14672715.2018. 1479192 